\title{
Huracanes y Mosquitos 1
}

\author{
Jorge Rey y Roxanne Rutledge ${ }^{2}$
}

\section{¿Por qué hay Tantos Mosquitos en Florida después de un Huracán?}

Los mosquitos pasan a través de cuatro etapas de desarrollo durante su vida: huevo, larva, pupa y adulto. Docenas de especies de mosquitos residen en Florida, y diferentes especies tienen diferentes medios para sobrevivir.

Además de todas las variables ambientales, existen dos características biológicas relacionadas con la puesta de huevos por mosquitos que determinan el número de mosquitos que se verán y sentirán después de un huracán. Estas características separan a las especies de mosquitos dependiendo en las condiciones bajo las cuales pondrán sus huevos. Los dos grupos son los mosquitos de inundación, y los mosquitos de aguas estancadas.

\section{Mosquitos de Inundación}

Muchas personas asocian a los mosquitos solamente con aguas estancadas porque creén que los mosquitos necesitan agua para depositar sus huevos. En realidad, los huevos de los mosquitos solo necesitan agua para "empollar" - pero algunas especies depositan sus huevos en suelos húmedos, pero sin agua en la superficie. En algunos casos los huevos se tienen que secar antes de podes continuar su desarrollo. Este tipo de huevo pertenece a los mosquitos de inundación.

Mucho antes de que estos mosquitos se noten, las hembras ya estaban al ala, alimentándose de sangre y poniendo huevos (hasta 200 huevos por camada) en sitios húmedos de pastizales, campos agrícolas, humedales y zanjas. Estos sitios, y también los huevos, eventualmente se secan y los huevos quedan encajonados en las ranuras y espacios del barro seco. Los huevos sobreviven en el barro seco durante el invierno y primavera. Luego de lluvias asociadas con tormentas y huracanes, estos sitios se vuelven a inundar y el agua que alcanza a los huevos, provee la señal de continuar el desarrollo.

Uno puede estimar la extensión de este tipo de habitáculo en Florida si se considera la cantidad de tierra en el estado que es pastizal, campo agrícola, humedal o tierra llana sin habitantes. Se estima que el número de huevos de mosquitos en habitáculos de inundación es de 0.7 a 1.3 millones por acre. Aún si solo un porcentaje pequeño de estos huevos completan el desarrollo, el número de mosquitos

1. Este documento con la identificación: ENY-719S, es uno de una serie de publicaciones del Departamento de Entomology and Nematology, del Servicio de Extensión Cooperativo de la Florida, del Instituto de Alimentos y Ciencias Agrícolas, universidad de la Florida. Publicado por primera vez en Febrero 25, 2004. Por favor, visite la dirección en la Red EDIS en 〈http://edis.ifas.ufl.edu〉.

2. Jorge R. Rey, Professor, C. Roxanne Rutledge, Assistant Professor, Florida Medical Entomology Laboratory, Vero Beach, FL; Entomology and Nematology Department, Cooperative Extension Service, Institute of Food and Agricultural Sciences, University of Florida, Gainesville, 32611. 
adultos producido es enorme. Desafortunadamente deshacerse de recipientes y sitios cerca del hogar que mantienen agua estancada no contribuye a la reducción de mosquitos de inundación.

\section{Mosquitos de Agua Estancada}

Los mosquitos que no pertenecen al grupo de inundación depositan sus huevos en aguas superficiales. Los huevos de este tipo de mosquito no resisten secarse. Si el sitio se seca antes de que los mosquitos completen su desarrollo, los huevos mueren.

Por largo tiempo, el agua traída por las copiosas lluvias asociadas con los huracanes del 2004 en Florida no tenía sitio para drenar y se mantuvo sobre la superficie, lo cual creó amplios habitáculos para la cría de mosquitos de aguas estancadas.

Las hembras de estos mosquitos ponen los huevos en la superficie del agua, y estos empollan en 24 horas más o menos. El agua es necesaria para completar el desarrollo durante el cual las larvas se convierten en pupas y luego en mosquitos adultos. Luego de aparearse y encontrar una fuente de sangre, las nuevas hembras comienzan el ciclo de nuevo al depositar sus huevos en el agua superficial.

\section{Doble Golpe}

La combinación de los hábitos de oviposición de estos dos grupos de mosquitos proveen un doble golpe ya que cuando las áreas secas se inundan, los mosquitos de inundación empollan, y cuando las inundaciones no drenan rápidamente, los mosquitos de aguas estancadas tienen mas sitios donde poner sus huevos. Esto fué lo que ocurrió en Florida luego de los huracanes del 2004.

\section{¿Que Puede Hacer el Indivíduo para Reducir las Picadas de Mosquitos?}

Muchas personas saben que siempre se recomienda vaciar recipientes que acumulan agua. Pero este consejo solo aplica a recipientes bajo el cual uno tiene control, por ejemplo, platos de las mascotas, macetas, cubos y latas. Este es un buen consejo durante tiempos normales, pero no ayuda cuando cuatro huracanes han causado inundaciones en todos sitios. Los habitáculos que crían mosquitos creados por eventos de precipitación asociados con huracanes son demasiado grandes para ser impactados por acciones individuales. En estos casos es mejor dejar que las agencias de control de mosquitos emprendan las medidas de control adecuadas.

En condados que tienen programas de control de mosquitos, puede que la ayuda no séa inmediata debido a la gran extensión de áreas con las cuales hay que lidiar. Además, puede que las medidas de control no sean permanentes - recuerden que los mosquitos vuelan. Aunque medidas de control para eliminar mosquito se apliquen en un sitio, probablemente el sitio será re-infectado de otros lugares debido a la gran extensión de áreas inundadas en el estado.

La mejor manera de prevenir las picadas de mosquitos es usar un buen repelente en las partes del cuerpo expuestas. Frecuentemente se menciona usar mangas y pantalones largos, pero durante los cálidos atardeceres del verano y principios de otoño en Florida, esto a veces no es práctico, particularmente para aquellos que no tengan electricidad.

Otro consejo es permanecer dentro de su vivienda. Inspeccione su hogar para descubrir daños no ovios causados por la tormenta. Busque huecos en las telas metálicas de ventanas y puertas, inspeccione el techo y las ventanas para descubrir aberturas por las cuales los mosquitos puedan entrar a su casa. Si tiene mascotas que entran y salen, pase sus manos sobre su piel o pelo para remover mosquitos que ahí se encuentren antes de que entren a su hogar.

El mantra durante los cuatro huracanes del 2004 fué "por favor, tenga paciencia". Los esfuerzos de las agencias de control de mosquitos, el uso de repelentes, y quedarse bajo techo en las tardes disminuirán las picadas de mosquitos. El agua eventualmente drenará, y los días mas cortos y menos cálidos del otoño disminuirán la producción de mosquitos. 
La Universidad de Florida -IFAS mantiene

varias publicaciones relacionadas con mosquitos que pueden ayudar a reducir el impacto de los mosquitos como consecuencia de tormentas, como las del 2004. Entre ellas se encuentran:

Servicios y Aparatos para el Control de Mosquitos en Viviendas de Florida http://edis.ifas.ufl.edu/IN494

Repelentes contra Mosquitos http://edis.ifas.ufl.edu/IN476 